\title{
COMPETITIVIDAD MUNDIAL DE LA PRODUCCIÓN DE CHILE VERDE DE MÉXICO
}

\section{GLOBAL COMPETITIVENESS OF PRODUCTION OF MEXICO GREEN CHILI}

\author{
Manuel Caro Encalada \\ Universidad Autónoma \\ de Yucatán, México \\ mcencala@hotmail.com
}

\author{
Carlos Leyva Morales \\ Universidad Autónoma \\ de Yucatán, México \\ clmoral@uady.mx
}

José Ríos Santana

Universidad Autónoma

de Yucatán, México

werther@hotmail.com

\section{RESUMEN}

Se analiza el comportamiento del mercado internacional de los chiles verdes y su influencia sobre las exportaciones y la competitividad de México durante el periodo 1999-2009, con base en los indicadores de competitividad propuestos por el Instituto Interamericano de Cooperación para la Agricultura de Colombia (2005). Se encontró que la producción mundial de chiles verdes fue favorable para México al crecer, en promedio, 3.93\% en el periodo analizado. La producción de México, por su parte, se caracterizó por un comportamiento ascendente (en promedio $2.13 \%$ ), en cuanto al comercio exterior, sus exportaciones en el periodo fueron también crecientes (6.7\% en promedio). Se concluye que la tendencia favorable observada en la oferta y comercio mundial del chile verde de 1999 a 2009 se ha reflejado de manera importante en México, lo cual, a su vez, se evidencia en la alta competitividad de los pimientos nacionales, expresado en sus índices de transabilidad, de balanza comercial relativa y de especialización internacional, que le confieren una competitividad macroeconómica alta. 
Palabras clave: mercado internacional, exportaciones, competitividad revelada, chile verde, México.

\begin{abstract}
We analyzes the behavior of the international market of green chillies and its influence on exports and the competitiveness of Mexico during the period 1999-2009, based on the competitiveness indicators proposed by the Inter-American Institute for cooperation on Agriculture of Colombia (2005). It was found that global production of green chillies was favorable for Mexico; grew up in average $3.93 \%$ in the period analyzed. Mexico production was also marked by rising behaviour (average of $2.13 \%$ ) and as soon as its foreign trade, the behavior of their exports in the period was also growing (average of 6.7\%). It is concluded that the favorable trend observed in supply and the green chillies from 1999 to 2009 world trade has been reflected significantly in Mexico, which in turn is evidenced in the high competitiveness of national peppers, expressed in its transabilidad, relative trade balance and international specialization indexes that confers a high macroeconomic competitiveness.
\end{abstract}

Keywords: international market, exports, revealed competitiveness, green chillies, Mexico.

Clasificación JEL: C82, E21, E23, F14, Q11, Q17 


\section{INTRODUCCIÓN}

México cuenta con una amplia diversidad de chiles o ajís, caracterizados por su color, olor, sabor, picor y tamaños; 22 clases de chiles verdes y 12 de chile seco (principalmente de los tipo Capsicum Solanaceae, annum, frutescens y sinenses) hacen el repertorio de productos que el país ofrece durante todo el año, y cada estado tiene sus características muy particulares, por lo que algunos terrenos los destinan al cultivo del chile para deshidratado y otros para producto fresco y curtido (Inforural, 2010).

Las principales regiones productoras de chiles en México son:

a) Región norte y noreste. Alta tecnología. Por lo general tienen buenos rendimientos y productividad con base en la adopción de buena tecnología, tienen condiciones ambientales más o menos estables y adecuados canales de comercialización. En esta región sobresalen los estados de Chihuahua, Sinaloa, Sonora, Nayarit, Durango, Baja California, Baja California Sur y Sur de Tamaulipas, quienes producen chiles jalapeñosCapsicum annuum L.v., bell-Capsicum annuum L., serranos-Capsicum annuum cv. 'Serrano Sinahusia', cayenne- Capsicum frutescens, anaheimCapsicum annuum Linnaeus cv. 'Anaheim', güeros-Capsicum annuum var.L. y anchos-Capsicum annuum Linnaeus cv. 'Chile Mulato'. Esta región está especializada en la producción de chiles frescos para al consumo directo o la industria de proceso.

b) Región centro o bajío. Mediana tecnología. Comprende zonas tradicionales de producción de chiles para deshidratar (anchos mulatosCapsicum annuum Linnaeus cv. 'Chile Mulato', pasilla-Capsicum annuum L. var. annuum L. cv. 'Pasilla', puya- Capsicum annuum, guajillo- Capsicum annuum var. Annuum $L$ ); aun cuando se observa un creciente interés de producir para el mercado de frescos. Por lo general tienen tecnología de 
producción y los métodos de secado tradicionales, lo que ocasiona que tengan bajos rendimientos y productos de mala calidad. Los estados comprendidos en esta región son Aguascalientes, Guanajuato, Puebla, San Luis Potosí, Zacatecas y Querétaro.

c) Región sur y sureste. Baja tecnología. Se siembra principalmente de secano y humedad residual, lo que origina altos riesgos e inestabilidad de la producción. En las regiones de Veracruz, Oaxaca, Campeche y Quintana Roo (productoras de chiles jalapeños-Capsicum annuum L.v., serranos-Capsicum annuum cv. 'Serrano Sinahusia', costeños-Capsicum annuum var. Annuum L y habaneros-Capsicum chinense Jacq) algunos han disminuido su área sembrada o bien han permanecido estables; sin embargo, sus rendimientos aún continúan siendo bajos y no compiten en mercados exigentes de productos de calidad. A pesar de esta situación presenta signos visibles de cambio tecnológico (Inforural, 2012).

No existe un factor que por sí solo garantice el éxito en el cultivo de chiles verdes en México. Es la conjunción de factores de diversa índole los que hacen que el país sea una potencia en su producción, entre éstos, los diversos tipos de clima, los variados suelos y el agua disponible, que hacen que cada región tenga sus características muy peculiares y necesarias para este cultivo haciéndolo un producto de calidad (Inforural, 2010).

En la producción nacional del chile verde (Capsicum annuum) destacan los estados de Chihuahua, Sinaloa, Zacatecas y San Luis Potosí, como los de mayor participación en el volumen total, con 577, 301, 291 y 171 miles de toneladas, respectivamente, en 2011. Los cuatro estados en conjunto aportaron más de la mitad de la producción nacional de chile verde en ese año, con un porcentaje de participación de 62.9 (SAGARPA, 2012).

De las variedades de chiles verdes producidas en el país en 2011 destaca el chile jalapeño con 699 mil 657 toneladas, una participación de 
$32.8 \%$ en el país; que, junto con otras tres variedades: poblano $(10.0 \%)$, serrano (8.6\%) y bell peper (6.4\%), aportaron $57.8 \%$ de la producción nacional de ese mismo año (SAGARPA, 2012).

De acuerdo con cifras mundiales de comercio de la FAO, México fue el segundo lugar mundial en la producción de chile verde y el décimosegundo de chile seco para 2011 (FAOSTAT, 2012); sus principales clientes fueron Estados Unidos, Japón, Canadá, Reino Unido y Alemania (SAGARPA, 2012).

Por otro lado, la demanda del chile mexicano en el mercado internacional se ha incrementado. En 2011 el producto nacional fue adquirido por 52 países de los cinco continentes. En el ámbito mundial los principales importadores de chile verde en ese año, entre los que se encuentran algunos de los principales de México, fueron: Estados Unidos con 779,393 tons., Alemania con 351,622 toneladas. y el Reino Unido con 157,134 toneladas. Le siguieron en importancia Francia, Países Bajos, Canadá y la Federación de Rusia (FAOSTAT, 2012). Las exportaciones mexicanas de chiles y pimientos a Estados Unidos representaron más de 628 millones de dólares en 2011, 57\% procedente de invernadero (United States Departament of Agriculture, 2012).

Es importante señalar que el mercado extranjero tiene una marcada preferencia por los productos frescos en cuanto a chiles verdes; de los productos comercializados $82.9 \%$ presenta esa característica. La demanda se completa con el consumo de chiles preparados, en vinagre o ácido, y secos con una cuota de 16.8 por ciento (FAO, 2010). Estados Unidos compra a México $98.9 \%$ de morrón, $81.2 \%$ de ancho o Anaheim seco y $92.1 \%$ de los preparados. En tanto que casi la totalidad de estos productos que se exportan a Reino Unido, Japón y Alemania son de conserva (Inforural, 2010).

Dado el anterior contexto, el presente trabajo se planteó como objetivo el analizar la relación entre el comportamiento del mercado mundial 
del chile verde durante los años 1999 al 2009 y la producción, exportación y competitividad del subsector chilero nacional, por medio de los índices de transabilidad, balanza comercial relativa y especialización internacional.

Para tales fines el estudio, despues de la introducción, se organizó en siete secciones, en la primera se explican las bases teoricas del enfoque de la competitividad revelada y sus principales indicadores de medición. En la segunda se presenta la metodología empleada para el acopio y análisis de los resultados del trabajo. La siguiente sección inicia la presentación de los resultados encontrados con el análisis de la producción mundial de este cultivo agrícola. En tanto que en el siguiente apartado se valora el comportamiento de su produccion por regiones del mundo. La quinta sección analiza el papel de México en la producción y exportación mundial del chile verde. En el penúltimo apartado se estudian los indicadores de competitividad de los principales países productores del cultivo en cuestión. Finalmente, se presenta un apartado de conclusiones.

\section{MARCO TEÓRICO}

El tema de la competitividad del sector agropecuario ha sido objeto de múltiples estudios con metodologías que han cambiado a lo largo de los años. A partir de 1999 gana terreno la medición con el índice de la competitividad revelada, basada en la teoría de Bela Balassa (1965) y desarrollada por Vollrath del United States Departament of Agriculture (Vollrath, 1987).

El enfoque de la competitividad revelada mide y analiza ex post los factores asociados al nivel de competitividad internacional del producto considerado. Compara la eficiencia en el uso de los recursos, revelada para cada país por su flujo comercial y donde es más eficiente aquel con el me- 
nor costo de oportunidad. Por lo tanto, representa el resultado de la asignación en la economía y refleja su posición en el mercado (Wollrath, 1987). Los indicadores de medición de la competitividad que considera son:

a) Indicador de transabilidad. Este mide la relación entre la balanza comercial neta y el consumo aparente, es decir, la participación de las exportaciones o las importaciones en el consumo de un país. Algebraicamente se expresa como:

$$
\mathrm{T} i j=(\mathrm{X} i j-\mathrm{M} i j) /(\mathrm{Q} i j+\mathrm{M} i j-\mathrm{X} i j)
$$

Donde: $\mathrm{X} i j=$ exportaciones del producto $i$ del país $j$

Mij $=$ importaciones del producto $i$ del país $j$.

Q $i j=$ producción del bien $i$ en el país $j$.

Cuando Tij es mayor que cero, el sector se considera exportador ya que existe un exceso de oferta [(Xij-Mij) $>0$ ], e indica que el producto es competitivo en el mercado (Durán y Alvarez, 2008). Dicho indicador se construye sobre otros dos subindicadores, el grado de apertura exportadora, que comprende la participación de las exportaciones de un producto sobre el consumo aparente, y de esta manera se refiere al grado de inserción en un mercado específico; y el grado de penetración de las importaciones, que muestra la relación entre las importaciones de un bien o sector y su consumo doméstico aparente.

b) Indicador de balanza comercial relativa. Este se interpreta como un índice de ventaja competitiva y se alcanza cuando un sector productivo exporta más de lo que importa, en cuyo caso el índice presenta un valor positivo. En forma algebraica se expresa como:

$$
\mathrm{BCR} i j=(\mathrm{X} i j-\mathrm{M} i j) /(\mathrm{X} i j+\mathrm{M} i j)
$$


$\mathrm{Si}$ es mayor que cero, se trata de un sector exportador y, por ende, competitivo. Si es menor que cero se trata de un sector importador y carente de competitividad frente al mercado internacional (Durán y Alvarez, 2008).

c) Indicador de especialización internacional de Lafay (1979). Establece la participación del saldo de la balanza comercial de los productos de un país en el total de las exportaciones mundiales, lo que permite examinar la vocación exportadora de cada país y la capacidad del mismo para construir ventajas competitivas permanentes. Su expresión algebraica es:

$$
\mathrm{IE}=(\mathrm{X} i j-\mathrm{M} i j) / \mathrm{X} i m
$$

Donde: $\mathrm{Xim}=$ exportaciones del bien $i$ realizadas por el mundo.

La alta especialización internacional se alcanza para un producto cuando el saldo de la balanza comercial se aproxima al total de la exportación mundial. Es decir, que si este valor es igual o superior a la unidad, el país es un exportador neto del bien en cuestión, y a mayor nivel, más importantes son las exportaciones como destino de la producción nacional del mismo. Si el indicador es negativo el país no tiene especialización y presenta dificultades competitivas.

Estos indicadores también son propuestos por el Instituto Interamericano de Cooperación para la Agricultura de Colombia (IICA, 2005), los cuales con base en las relaciones que se derivan del esquema de una matriz previamente construida permitieron realizar el análisis de la ventaja competitiva del sistema de producción de chiles verdes de México. 


\section{METODOLOGÍA}

Para el desarrollo del presente trabajo se utilizó un diseño de comprobación de hipótesis no experimental longitudinal en su variante de análisis de tendencia (Hernández, Fernández y Baptista, 2010).

La hipótesis que se buscó validar fue la siguiente: la tendencia en la oferta y la demanda mundial del chile verde durante los años 1999 a 2009 se ve reflejada hacia México en su volumen y valor de exportación de estos productos y en la competitividad del subsector chilero nacional expresado en los indicadores positivos de transabilidad, de balanza comercial relativa y de especialización internacional.

Se realizó una revisión de la literatura de las diferentes fuentes de información secundarias disponibles en México (SEDEINCO, INEGI y SAGARPA), así como de la existente en los bancos de información disponibles en internet.

En la recolección de la información básica se utilizó como instrumento una bitácora de trabajo, la cual consideró los siguientes apartados de información: producción mundial, producción nacional, exportación e importación de chiles verdes en el mercado mundial y exportación e importación de chiles verdes en el mercado nacional (FAOSTAT, 2011).

La información recopilada se ordenó, clasificó y procesó por medio de una hoja de cálculo electrónica (Excel), misma que permitió la estimación de los coeficientes estadísticos e indicadores matemáticos de comportamiento (Kasmier, 2000) planteados para el estudio (valores promedio y tasas de cambio).

En cuanto a la estimación y jerarquización de los indicadores de competitividad de los chiles verdes, se realizó empleando la base de datos de FAOSTAT, el periodo considerado fue de 1999 a 2009, por la disponibilidad de las cifras de interés de comercio exterior en la base de datos citada. 


\section{PRODUCCIÓN MUNDIAL}

El volumen de la producción mundial de chiles verdes presentó una tendencia hacia arriba en el periodo 1999-2009 al pasar de un total de producción de 19, 417,763 toneladas en 1999 a 28, 843,822 en 2009 (cuadro 1). La producción total registró un crecimiento de $46.69 \%$ en el periodo, originado por diversos factores, entre los principales: el aumento del consumo de esta hortaliza en la dieta de la población de los diversos continentes, así como por las propiedades que se le atribuyen en la actualidad a los pimientos, que han diversificado sus campos de aplicación y, con ello, aumentado los requerimientos del mismo en el mundo.

\section{Cuadro 1}

Producción mundial de chile verde

\begin{tabular}{|c|c|c|}
\hline Años & $\begin{array}{c}\text { Producción mundial } \\
\text { (toneladas) }\end{array}$ & $\begin{array}{c}\text { Tasa de cambio } \\
\%\end{array}$ \\
\hline 1999 & $19,417,763$ & - \\
\hline 2000 & $20,860,503$ & 7.43 \\
\hline 2001 & $21,426,460$ & 2.71 \\
\hline 2002 & $22,494,964$ & 4.99 \\
\hline 2003 & $24,310,551$ & 8.07 \\
\hline 2004 & $24,558,523$ & 1.02 \\
\hline 2005 & $25,231,445$ & 2.74 \\
\hline 2006 & $26,582,977$ & 5.36 \\
\hline 2007 & $27,409,186$ & 3.11 \\
\hline 2008 & $28,026,980$ & 2.25 \\
\hline 2009 & $28,483,822$ & 1.63 \\
\hline
\end{tabular}

Fuente: Elaboración propia con datos de FAOSTAT, 2011.

En el periodo considerado se puede observar también que se registró un comportamiento decreciente e irregular en la tasa de crecimiento de la producción mundial de chiles verdes, ya que mientras para el año 2000 ésta registró una tasa de variación de $7.43 \%$ (la segunda más alta en el periodo, 
sólo después de 2003 de 8.07\%), al año siguiente la tasa desciende drásticamente, al alcanzar un valor de sólo $2.7 \%$; situación que se repite a lo largo del periodo y en el año 2009 finaliza con 1.63\%. La tasa de crecimiento media anual de la producción mundial de esta hortaliza fué de 3.93 por ciento.

Los parámetros presentados evidencian que la producción de chiles ha sido dinámica en el contexto agrícola internacional en los últimos once años. Por ejemplo, contrasta con la producción de trigo, la cual creció a una tasa promedio anual de únicamente $1.64 \%$ en el periodo de referencia, o con la del arroz en cáscara que tuvo una tasa anual de crecimiento de $1.10 \%$; mientras la población lo hizo a una tasa de 2.6\% (6,800 millones de personas) durante 1999- 2009 (FAOSTAT, 2012).

Por otra parte, el ritmo de crecimiento de la producción mundial de chiles se explica principalmente por la variación de la superficie cosechada, al pasar de 1.58 millones de hectáreas en 1999 a 1.88 millones en 2009 (cuadro 2); el área de cultivo creció aproximadamente a una tasa promedio anual de 1.75 por ciento.

\section{Cuadro 2}

Superficie cosechada mundial del chile verde 1999-2009

\begin{tabular}{|c|c|c|}
\hline Años & Área cosechada (ha) & Tasa de cambio \\
\hline 1999 & $1,582,730$ & - \\
\hline 2000 & $1,623,596$ & 2.58 \\
\hline 2001 & $1,604,949$ & -1.15 \\
\hline 2002 & $1,676,132$ & 4.43 \\
\hline 2003 & $1,724,518$ & 2.89 \\
\hline 2004 & $1,686,929$ & -2.18 \\
\hline 2005 & $1,731,778$ & 2.66 \\
\hline 2006 & $1,763,008$ & 1.80 \\
\hline 2007 & $1,767,667$ & 0.26 \\
\hline 2008 & $1,825,941$ & 3.30 \\
\hline 2009 & $1,879,078$ & 2.91 \\
\hline \multicolumn{2}{|c|}{ Tasa media de crecimiento } & $1.75 \%$ \\
\hline
\end{tabular}

Fuente: Elaboración propia con datos de FAOSTAT, 2011. 
En contraste, los rendimientos por hectárea pasaron de 12.26 a 15.15 toneladas durante el periodo, con una tasa de crecimiento anual de $2.16 \%$ (cuadro 3). Con base en la magnitud de estos dos parámetros se puede señalar que el aumento que experimentó la producción de chiles verdes derivó de cambios tecnológicos relevantes en el cultivo, ya que el rendimiento o productividad al crecer más que la superficie cultivada le confiere a la primera variable la importancia ya señalada.

\section{Cuadro 3}

Rendimiento mundial del chile verde

\begin{tabular}{|c|c|c|}
\hline Años & Rendimiento $(\mathrm{kg} / \mathrm{ha})$ & Tasa de cambio \\
\hline 1999 & $12,268.5$ & 4.73 \\
\hline 2000 & $12,848.3$ & 3.91 \\
\hline 2001 & $13,350.2$ & 0.53 \\
\hline 2002 & $13,420.7$ & 5.04 \\
\hline 2003 & $14,097.0$ & 3.27 \\
\hline 2004 & $14,558.1$ & 0.08 \\
\hline 2005 & $14,569.6$ & 3.49 \\
\hline 2006 & $15,078.1$ & 2.84 \\
\hline 2007 & $15,505.8$ & -1.01 \\
\hline 2008 & $15,349.3$ & -1.24 \\
\hline 2009 & $15,158.3$ & $2.16 \%$ \\
\hline \multicolumn{2}{|c|}{ Tasa media de crecimiento } & \\
\hline
\end{tabular}

Fuente: Elaboración propia con datos de FAOSTAT, 2011

En la gráfica 1 se observa la tendencia general que ha seguido tanto el rendimiento por hectárea como la superficie cosechada. Como se puede observar el rendimiento creció a un ritmo inferior al de la superficie sólo en el lapso de 1999 a 2003. Sin embargo, en el periodo posterior (2004$2008)$ su tasa de crecimiento promedio anual (1.73\%) fue superior a la de la superficie $(1.17 \%)$, inclusive ésta experimentó en términos absolutos un considerable incremento en los años 2006 y 2007. 


\section{Gráfica 1}

Superficie cosechada y rendimiento mundial de chile verde 1999-2009

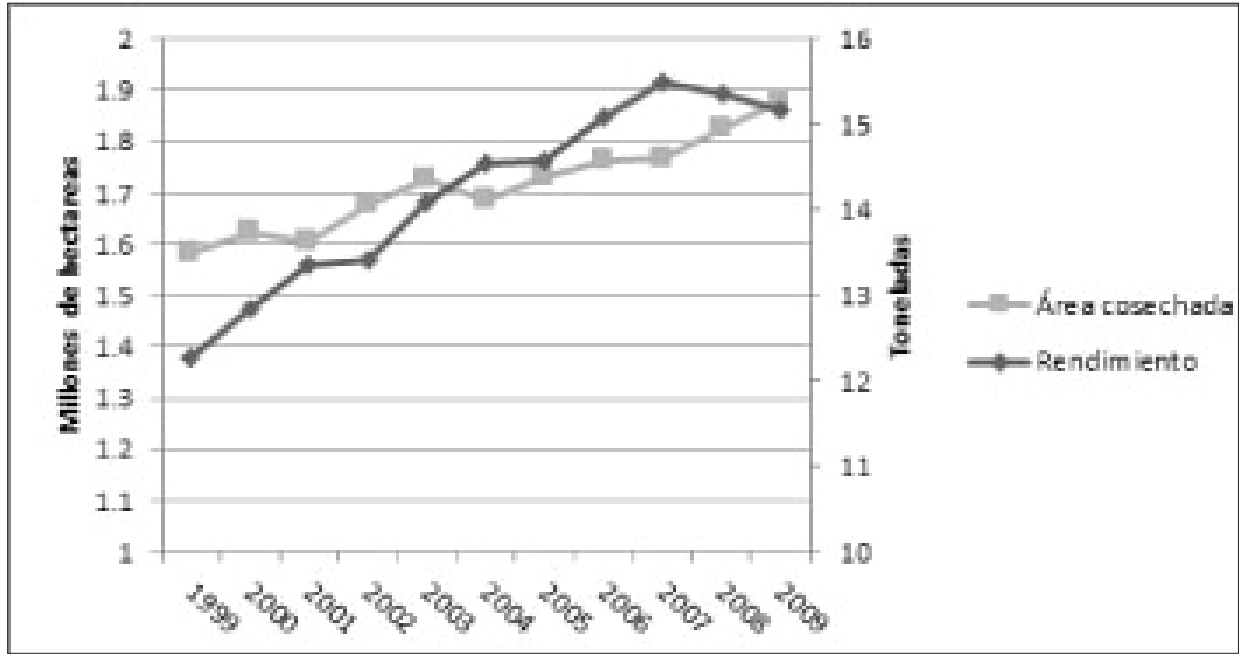

Fuente: Elaboración propia con datos de FAOSTAT, 2011

Como se observa en el cuadro 4, el principal país productor de chiles verdes en el mundo, y de Asia, es China, el volumen de su producción ascendió a 14,524,178 millones de toneladas en 2009 y creció casi dos veces con respecto a 1999. Asimismo, el citado volumen representó 50.99\% de la producción mundial, mientras que en 1999 representaba únicamente $40.38 \%$. Las cifras manifiestan la importancia económica que ha adquirido este país asiático en el contexto mundial. 


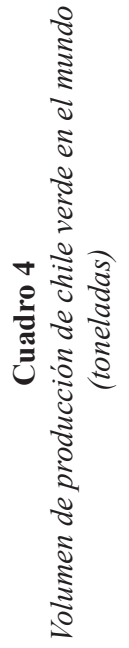

\begin{tabular}{|c|c|c|c|c|c|c|c|c|c|c|c|c|c|c|c|c|}
\hline 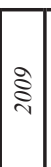 & 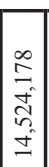 & $\mid \begin{array}{c}\hat{2} \\
\hat{o} \\
\hat{o} \\
\hat{i}\end{array}$ & $\mid \begin{array}{l}\tilde{\delta} \\
\tilde{\delta} \\
\hat{\tilde{\delta}} \\
- \\
-\end{array}$ & 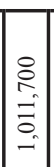 & 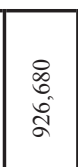 & $\begin{array}{l}\stackrel{8}{0} \\
\stackrel{-}{0} \\
\stackrel{-}{-1}\end{array}$ & $\begin{array}{c}n \\
\hat{\sigma} \\
\hat{i} \\
\sigma \\
\sigma\end{array}$ & 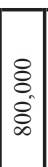 & $\begin{array}{l}\stackrel{8}{0} \\
\stackrel{n}{*} \\
\Rightarrow\end{array}$ & $\mid \begin{array}{l}0 \\
0 \\
0 \\
0 \\
\tilde{n} \\
\end{array}$ & 怘 & $\begin{array}{c}\cong \\
\stackrel{5}{5} \\
=\end{array}$ & 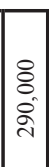 & $\begin{array}{l}q \\
\dot{a} \\
\infty \\
m \\
m\end{array}$ & 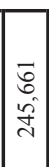 & 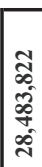 \\
\hline 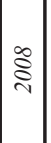 & 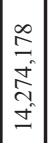 & 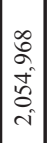 & 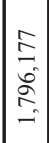 & 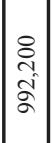 & $\begin{array}{l}\stackrel{0}{\infty} \\
\stackrel{0}{a} \\
\stackrel{0}{0}\end{array}$ & $\begin{array}{l}\stackrel{n}{=} \\
\stackrel{\vec{\alpha}}{\delta} \\
\stackrel{-}{-}\end{array}$ & 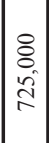 & 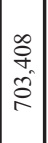 & 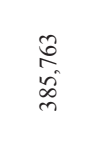 & $\mid \begin{array}{l}\hat{\beth} \\
\hat{\jmath} \\
\tilde{j}\end{array}$ & $\begin{array}{l}\stackrel{8}{0} \\
\dot{0} \\
\text { m }\end{array}$ & 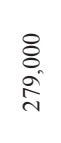 & 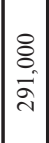 & 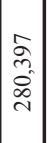 & $\begin{array}{l}\tilde{O} \\
0 \\
0 \\
\infty \\
\tilde{\nu}\end{array}$ & 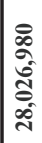 \\
\hline ڤे & 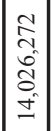 & 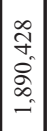 & 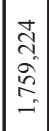 & \begin{tabular}{c|} 
\\
$\tilde{n}$ \\
$\tilde{n}$ \\
$\tilde{n}$ \\
- \\
-
\end{tabular} & 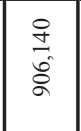 & 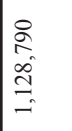 & 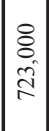 & 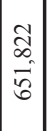 & $\begin{array}{l}\stackrel{0}{0} \\
\stackrel{\vec{J}}{F}\end{array}$ & 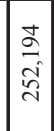 & 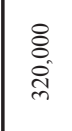 & 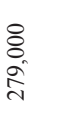 & $\begin{array}{c}8 \\
\stackrel{8}{0} \\
\infty \\
\stackrel{0}{\sim} \\
\end{array}$ & 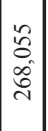 & $\begin{array}{l}0 \\
\tilde{\sigma} \\
\dot{+} \\
- \\
-\end{array}$ & 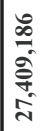 \\
\hline ¿̊̀ & 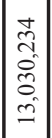 & $\begin{array}{c}\hat{N} \\
\hat{\sim} \\
\overrightarrow{0} \\
\stackrel{0}{-} \\
-\end{array}$ & 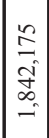 & 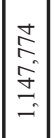 & $\begin{array}{l}\stackrel{\circ}{2} \\
\stackrel{\infty}{\infty} \\
\stackrel{\alpha}{a}\end{array}$ & $\begin{array}{l}8 \\
8 \\
0 \\
\infty \\
= \\
=\end{array}$ & 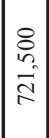 & $\begin{array}{l}8 \\
\vdots \\
\circ \\
i n \\
n\end{array}$ & $\begin{array}{l}\stackrel{0}{\circ} \\
\text { ते } \\
\text { rn }\end{array}$ & 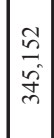 & $\begin{array}{l}\stackrel{8}{0} \\
\frac{\infty}{m}\end{array}$ & $\begin{array}{l}\stackrel{8}{\Xi} \\
\stackrel{-}{*} \\
\stackrel{N}{N}\end{array}$ & 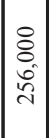 & $\begin{array}{l}\infty \\
\infty \\
\infty \\
\stackrel{2}{\sim} \\
\sim\end{array}$ & $\begin{array}{l}\stackrel{0}{7} \\
\stackrel{7}{2} \\
\stackrel{2}{\sim}\end{array}$ & 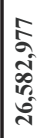 \\
\hline ڤે & 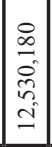 & 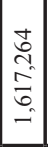 & 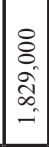 & 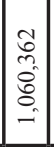 & $\begin{array}{l}\text { 尺 } \\
0 \\
\text { à }\end{array}$ & $\begin{array}{l}\widetilde{0} \\
0 \\
\infty \\
0 \\
0 \\
-1\end{array}$ & $\begin{array}{l}\stackrel{8}{0} \\
\stackrel{-}{\mathbb{N}}\end{array}$ & $\begin{array}{l}8 \\
8 \\
0 \\
\dot{0} \\
+ \\
+\end{array}$ & $\begin{array}{l}\text { సे } \\
\text { ñ } \\
\text { ले }\end{array}$ & 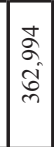 & $\begin{array}{l}8 \\
\vdots \\
\text { in } \\
\text { f }\end{array}$ & 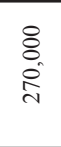 & 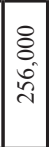 & 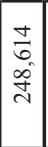 & $\begin{array}{l}\vec{n} \\
\hat{n} \\
\stackrel{\tilde{N}}{2}\end{array}$ & 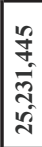 \\
\hline 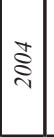 & 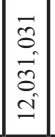 & 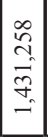 & $\begin{array}{l}8 \\
8 \\
8 \\
8 \\
\stackrel{8}{0} \\
-\end{array}$ & 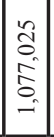 & $\begin{array}{l}8 \\
\infty \\
\infty \\
\infty \\
\vdots \\
\alpha\end{array}$ & $\begin{array}{l} \pm \\
\stackrel{ \pm}{n} \\
\stackrel{8}{0} \\
=\end{array}$ & 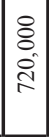 & $\mid \begin{array}{c}\tilde{r} \\
\tilde{f} \\
\tilde{b} \\
\dot{q}\end{array}$ & $\begin{array}{l}\overrightarrow{0} \\
\text { Na } \\
\stackrel{\vec{f}}{\sigma}\end{array}$ & $\mid \begin{array}{l}0 \\
\tilde{n} \\
i \\
i \\
\tilde{n}\end{array}$ & $\begin{array}{l}\stackrel{8}{0} \\
\infty \\
\infty \\
\infty\end{array}$ & 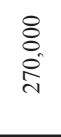 & $\begin{array}{l}8 \\
8 \\
\vdots \\
2 \\
\end{array}$ & 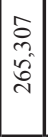 & 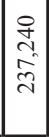 & $\begin{array}{l}3 \\
\tilde{n} \\
\infty \\
\infty \\
n \\
n \\
\tilde{N}\end{array}$ \\
\hline ڤి & 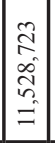 & $\begin{array}{c}0 \\
0 \\
0 \\
\tilde{n} \\
\infty \\
- \\
-1\end{array}$ & $\begin{array}{l}8 \\
8 \\
0 \\
\stackrel{0}{2} \\
-\end{array}$ & $\begin{array}{c}\vec{\infty} \\
\overrightarrow{0} \\
0 \\
0 \\
- \\
-\end{array}$ & 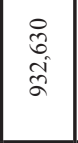 & $\begin{array}{l}\underset{1}{0} \\
\widehat{0} \\
\stackrel{0}{0} \\
-\end{array}$ & 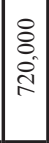 & $\begin{array}{l}\tilde{1} \\
\hat{n} \\
o \\
o \\
\sigma\end{array}$ & $\begin{array}{l}\frac{1}{ \pm} \\
\overrightarrow{0} \\
m \\
m\end{array}$ & 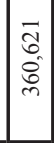 & $\begin{array}{l}\stackrel{8}{0} \\
\text { in } \\
m\end{array}$ & 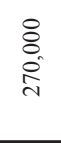 & 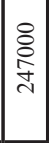 & 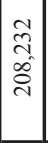 & 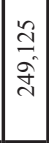 & 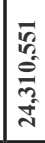 \\
\hline 今े & \begin{tabular}{|c|c|}
$\vec{\infty}$ \\
0 \\
0 \\
0 \\
0 \\
0 \\
0
\end{tabular} & 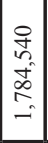 & 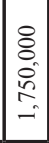 & 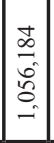 & \begin{tabular}{l}
8 \\
\multirow{0}{0}{} \\
$\infty$ \\
$\infty$ \\
$\infty$
\end{tabular} & $\begin{array}{l}2 \\
0 \\
i \\
\hat{\sigma}\end{array}$ & $\begin{array}{l}8 \\
\stackrel{0}{0} \\
\stackrel{1}{1} \\
\end{array}$ & 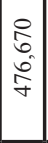 & 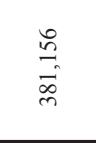 & $\mid \begin{array}{l}0 \\
0 \\
\infty \\
0 \\
0 \\
n \\
m\end{array}$ & $\begin{array}{l}8 \\
8 \\
0 \\
m\end{array}$ & $\begin{array}{l}\stackrel{8}{0} \\
\stackrel{\circ}{2}\end{array}$ & 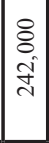 & 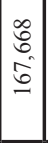 & 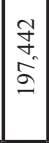 & 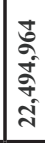 \\
\hline ఫ్ & 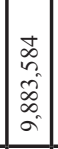 & \begin{tabular}{|c|}
8 \\
$\infty$ \\
$\infty$ \\
0 \\
$\infty$ \\
$\infty$ \\
- \\
\end{tabular} & \begin{tabular}{|l|} 
\\
8 \\
0 \\
0 \\
0 \\
- \\
- \\
\end{tabular} & $\mid \begin{array}{l}\vec{n} \\
\vec{a} \\
\hat{a}\end{array}$ & 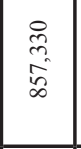 & 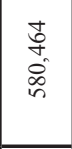 & 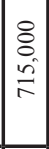 & $\begin{array}{l}\hat{\infty} \\
0 \\
0 \\
\infty \\
\infty \\
\infty\end{array}$ & 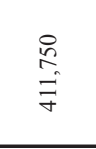 & 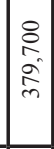 & $\begin{array}{l}\stackrel{8}{0} \\
\text { aे } \\
\text { in }\end{array}$ & $\begin{array}{l}\stackrel{8}{0} \\
\stackrel{0}{\circ} \\
\text { ป }\end{array}$ & 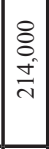 & $\begin{array}{l}\approx \\
n \\
2 \\
n \\
n\end{array}$ & \begin{tabular}{|l|}
$n$ \\
$\infty$ \\
$\infty$ \\
+ \\
$\infty$ \\
$-\infty$ \\
-1
\end{tabular} & 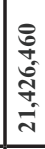 \\
\hline ‡ి & 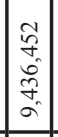 & 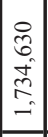 & 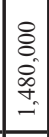 & 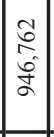 & $\begin{array}{l}\stackrel{2}{\alpha} \\
\text { ๙ิ }\end{array}$ & 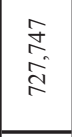 & 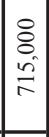 & 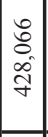 & 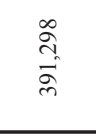 & 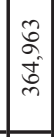 & 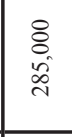 & $\begin{array}{l}\stackrel{8}{\circ} \\
\stackrel{\leftrightarrow}{\circ}\end{array}$ & $\begin{array}{l}\circ \\
\stackrel{8}{0} \\
\stackrel{0}{-}\end{array}$ & 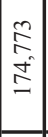 & $\mid \begin{array}{l}8 \\
8 \\
\infty \\
\pm \\
\pm \\
=\end{array}$ & 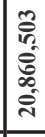 \\
\hline बे & 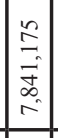 & 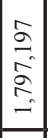 & \begin{tabular}{|c|} 
\\
0 \\
0 \\
0 \\
0 \\
- \\
- \\
\end{tabular} & 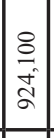 & 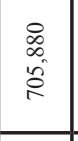 & $\begin{array}{l}\stackrel{0}{0} \\
\stackrel{0}{0} \\
0 \\
0\end{array}$ & 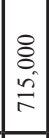 & 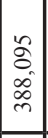 & $\begin{array}{l}\text { fo } \\
\text { o } \\
\text { f }\end{array}$ & 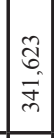 & 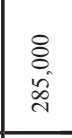 & 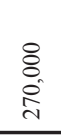 & \begin{tabular}{|c|}
8 \\
8 \\
$\infty$ \\
$\infty$ \\
- \\
\end{tabular} & $\begin{array}{l}n \\
\hat{n} \\
n \\
n \\
2\end{array}$ & 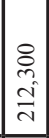 & 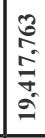 \\
\hline 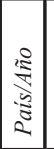 & 竭 & 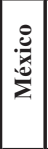 & 䋨 & 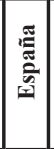 & 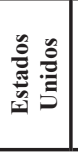 & 㚔 & 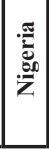 & 产 & 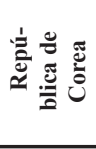 & 吾 & 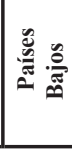 & 䒕 & 莺 & 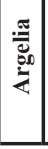 & 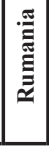 & $\stackrel{巳}{\stackrel{g}{g}}$ \\
\hline
\end{tabular}

ISSN 0188-266X - Revista de Economía - Vol. XXXI - Núm. 83 
Como se puede apreciar en el mismo cuadro, en total el volumen de producción de China se incrementó en 6,683,003 toneladas de 1999 a 2009 , al registrar una tasa media de crecimiento anual de $6.48 \%$. No fue así en el caso de México y Turquía, quienes registraron tasas inferiores de $2.13 \%$ y $2.42 \%$, respectivamente.

En este contexto, México es el país que ocupa el segundo lugar en la producción de chiles verdes, su participación en el total mundial fue de $7.38 \%$ en 2009 , pero no aumentó como en el caso de China, ya que su contribución en 1999 fue de 9.25\%. El tercer lugar lo ocupa Turquía al aportar $6.45 \%$ de la producción mundial en 2009. Cabe señalar que en el periodo 1999-2009 México se mantuvo en lo general como el segundo lugar mundial; a excepción del periodo de 2004 a 2006 en el que Turquía lo desplazó temporalmente, aunque la diferencia de producción entre ambos países no ha excedido $2.0 \%$ en promedio (gráfica 2). Los otros países que presentan una participación relativamente importante en la oferta mundial de este cultivo son: España (3.55\%), Estados Unidos (3.25\%) e Indonesia (3.90\%). En la gráfica también se puede observar que China (47.89\%), México (7.46\%) y Turquía (7.04\%), aportaron más de 60\% de la producción mundial en el lapso 1999-2009. 


\section{Gráfica 2}

Contribución porcentual promedio de los principales paises productores de chile verde, 1999-2009

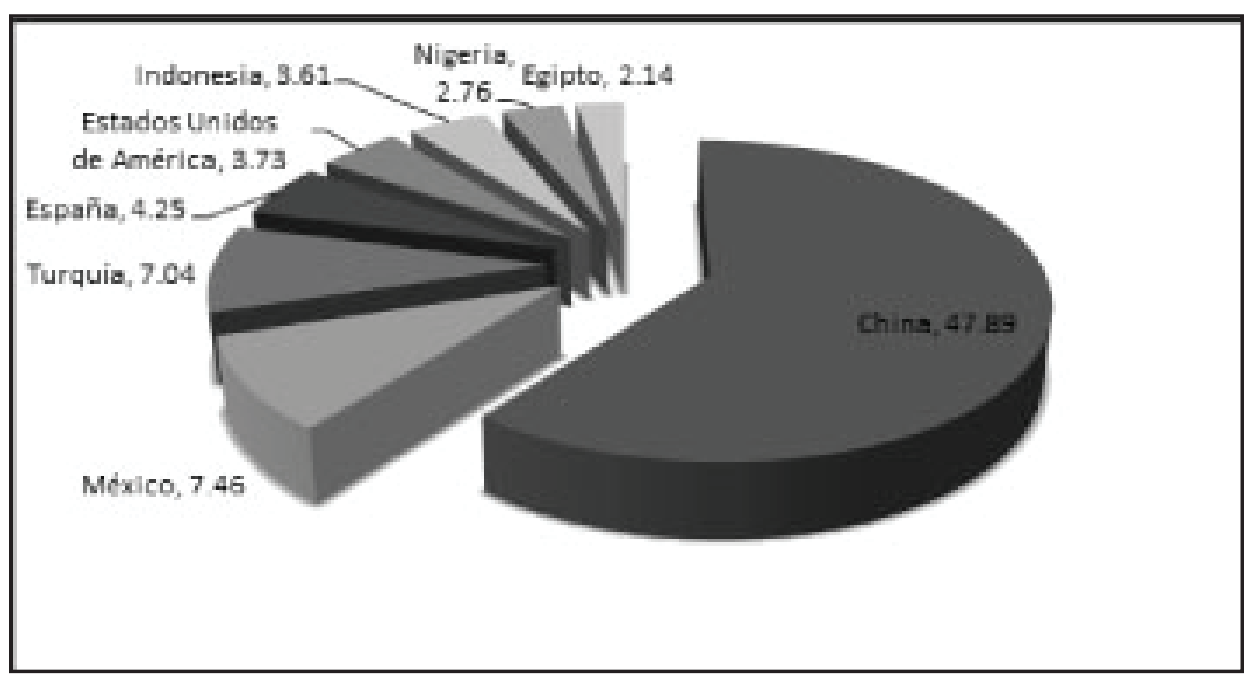

Fuente: Elaboración propia con datos de FAOSTAT 2011.

Los principales países productores de chiles verdes, en su mayoría, también son los que destacan como los que poseen el mayor número de superficie cultivada. Por ejemplo, China ocupa el primer lugar tanto por las hectáreas de superficie cultivada de pimientos como por su volumen, lo mismo ocurre con México y Turquía. Los otros países que si bien no coinciden en cuanto a su posición en la clasificación mundial, pero si reflejan participación de importancia en los dos rubros, son Indonesia y Nigeria. No es así en el caso de España y Estados Unidos, quienes de ocupar la cuarta y quinta posición en volumen descienden a la novena y décimosegunda posición en relación con la superficie cultivada. Esta divergencia es determinada por el diferente grado tecnológico de los diversos procesos de producción empleados en los dos últimos países (rendimiento por hectárea), aspecto asociado principalmente con el desarrollo científico de 
los mismos, los recursos naturales y con la disponibilidad y calidad de los insumos que emplean (IICA, 2005).

Por otra parte, se observó que el rendimiento promedio del cultivo de chiles (1999 - 2009) en los cinco principales países productores resultó generalmente mayor que el nivel promedio mundial (14.20 toneladas por hectárea). En China, por ejemplo, éste es de 19.89 toneladas por hectárea; en México de 15.06, en Turquía de 20.10, en España de 46.45 y en Estados Unidos de 27.73 toneladas por hectárea. Por lo tanto, los principales países productores no son los que tienen los mayores rendimientos por hectárea, ya que de los primeros cinco solamente España y Estados Unidos aparecen entre los 20 primeros lugares en este renglón. De igual manera, destacan los rendimientos promedio obtenidos en este periodo por Países Bajos, Bélgica, Reino Unido y Finlandia, países que, a pesar de no figurar entre los diez principales productores del mundo, reportaron altos rendimientos, 260.92, 213.90, 198.93 y 118.46 toneladas por hectárea, respectivamente. En los cuatro países se emplean tecnologías de punta, propias de procesos de producción altamente capitalizados (Samuelson y Nordhaus, 2010), situación que no ocurre por lo general en México, que ocupa el lugar 45, no obstante ser el segundo principal productor de chiles verdes en el mundo.

\section{PRODUCCIÓN POR REGIONES}

La gráfica 3 muestra que entre las cinco regiones del mundo, el continente asiático se encuentra como el de mayor aportación de la producción de chile verde mundialmente, en particular la obtenida de los países localizados en la parte este y sur de dicha región, donde este fruto forma parte de la cocina tradicional y se incluye en multitud de platillos; así la industria ha crecido 
en forma muy vertiginosa. La contribución de Asia a la producción mundial de chile verde pasó de $59.06 \%$ en 1999 a $66.01 \%$ en 2009; convirtiéndose en la región más dinámica en el ámbito mundial. En contraste, la mayoría de las otras regiones presentaron niveles de participación significativamente menores en esta producción y con una tendencia inclusive decreciente en su contribución: Europa -29\%, Oceanía -16.7\% y América -17.3 por ciento.

El continente americano ocupa el segundo lugar en el volumen de producción mundial del chile verde desde 1999; con una producción en ese año de 3,622,684 toneladas (12.72\% del total mundial). Sin embargo, esta región registró un comportamiento inestable y poco dinámico (tasa media de crecimiento de $2.07 \%$, sólo superada por Asia y África, 5.12\% y $3.93 \%$, respectivamente), con tasas de crecimiento comparativamente un poco más bajas que en las otras regiones, principalmente en los años 2002 y 2004, en los que registró valores negativos.

\section{Gráfica 3}

Producción de chile verde por continente, 1999-2009

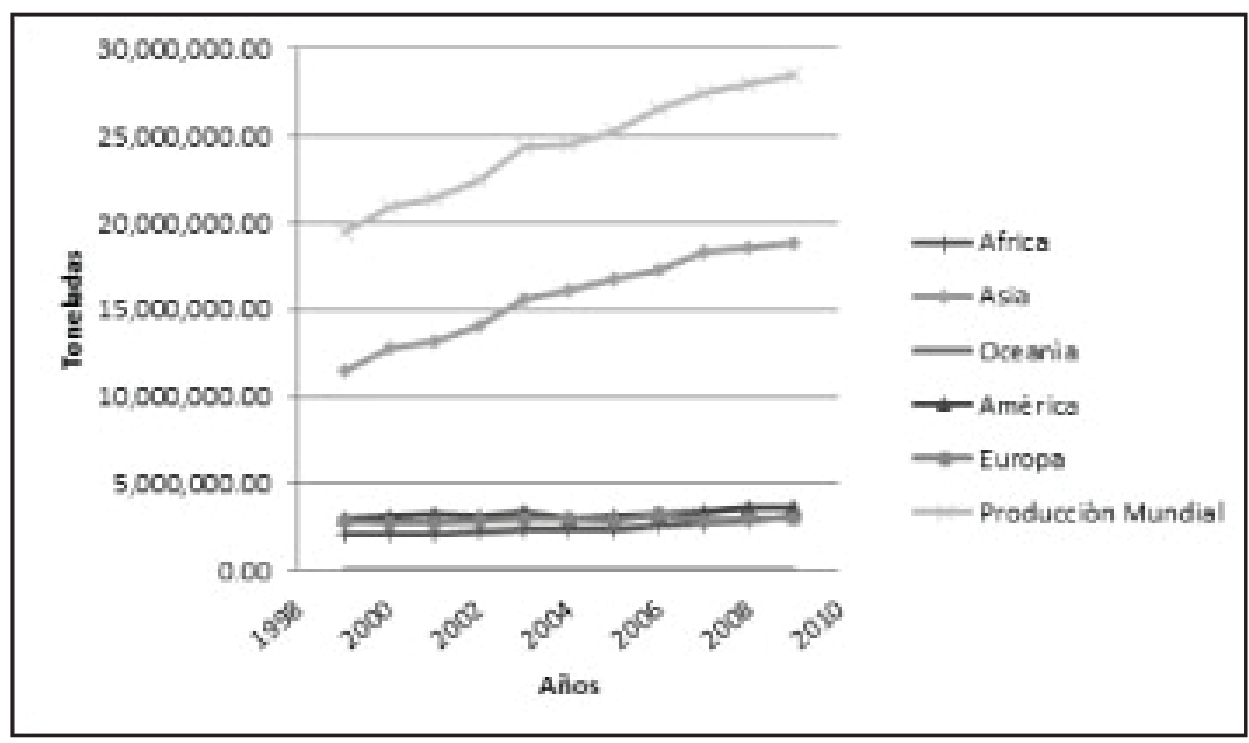

Fuente: Elaboración propia con datos de FAOSTAT, 2011. 
En cuanto a las áreas geográficas de América, se observa que la zona norte ocupa el primer lugar al contribuir, en promedio, con $84.16 \%$ en la producción total de chiles verdes de la región, para el periodo 19992009 (gráfica 4). Es importante mencionar que la mayor parte de la producción de chile verde del área de América del Norte la aporta México, con una contribución promedio de 65.4\%, le sigue en importancia Estados Unidos con 33\%; en tanto que de América del Sur, Argentina es el país más importante al contribuir con 34.1\%, seguido de Venezuela con 25.5\%. Asimismo, México al aportar $55.1 \%$ de la producción del continente americano se ubica como el principal país productor de la región; su volumen de producción es superior por más del triple de la producción conjunta de América Central, América del Sur y el Caribe, cifras que evidencian su importancia en este rubro.

La principal tasa media anual de crecimiento de la producción en la región de América del Norte de 1999 a 2009 la registró Estados Unidos que fue de $3.20 \%$ (superior a la tasa media de crecimiento de América del Norte que alcanzó 2.07\%), siguiéndole en importancia México con una tasa de 2.13 por ciento. 


\section{Gráfica 4}

Producción de chile verde por regiones de América

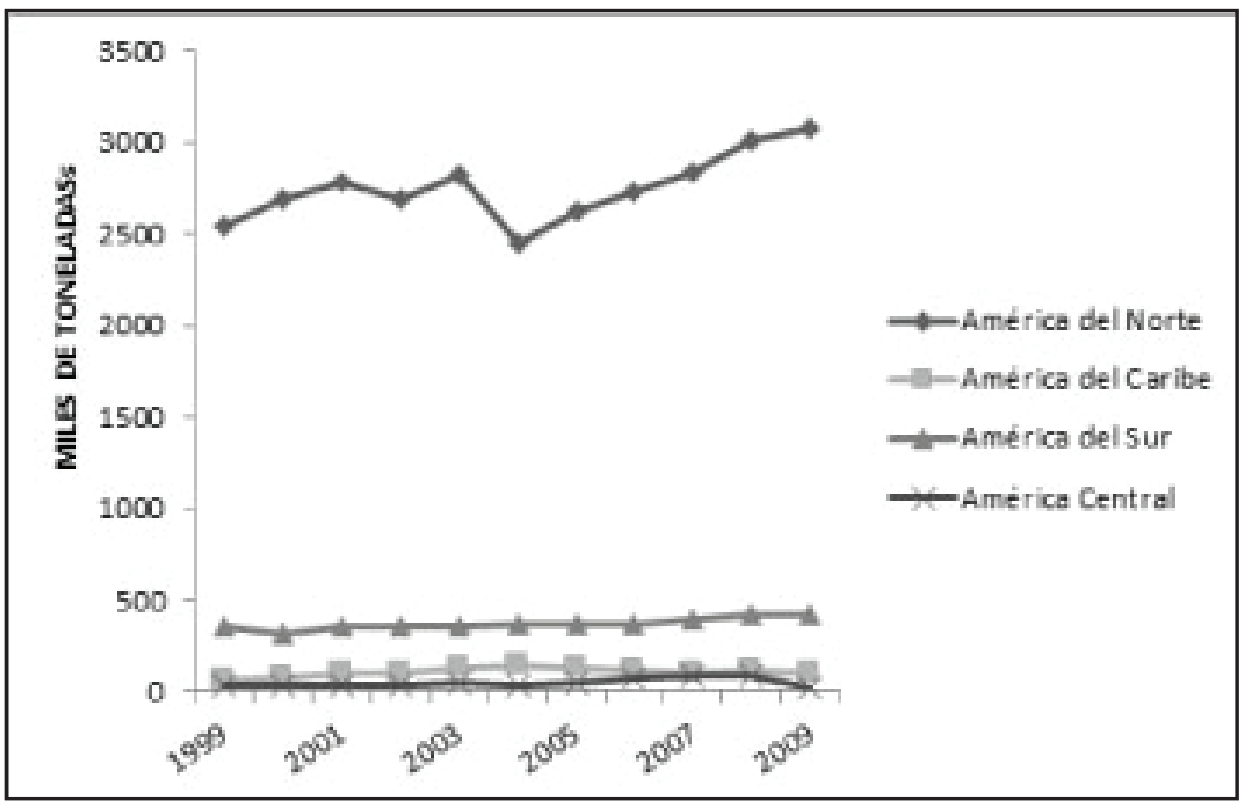

Fuente: Elaboración propia con datos de FAOSTAT, 2011.

\section{PRODUCCION Y EXPORTACION DE MÉXICO}

La producción de chile verde presentó una tendencia general hacia la alza, con altibajos, de 1999 a 2009, su incremento total fue de $17.05 \%$ al pasar de 1,797.1 a 2,103.7 miles de toneladas, volumen promedio anual de 1,801.8 miles de toneladas. El nivel de productividad por hectarea (15.06 toneladas) ubica a México en el $45^{\circ}$ lugar mundial.

En materia de comercio exterior, desde el año 2004 México es el país que encabeza la lista con un volumen de exportación que pasó de 325.58 a 608.64 miles de toneladas en el periodo que nos ocupa, lo que representó una participación promedio en el total mundial de $24.22 \%$. Cabe señalar que su contribución a esta oferta ha variado en forma no muy significativa, ya 


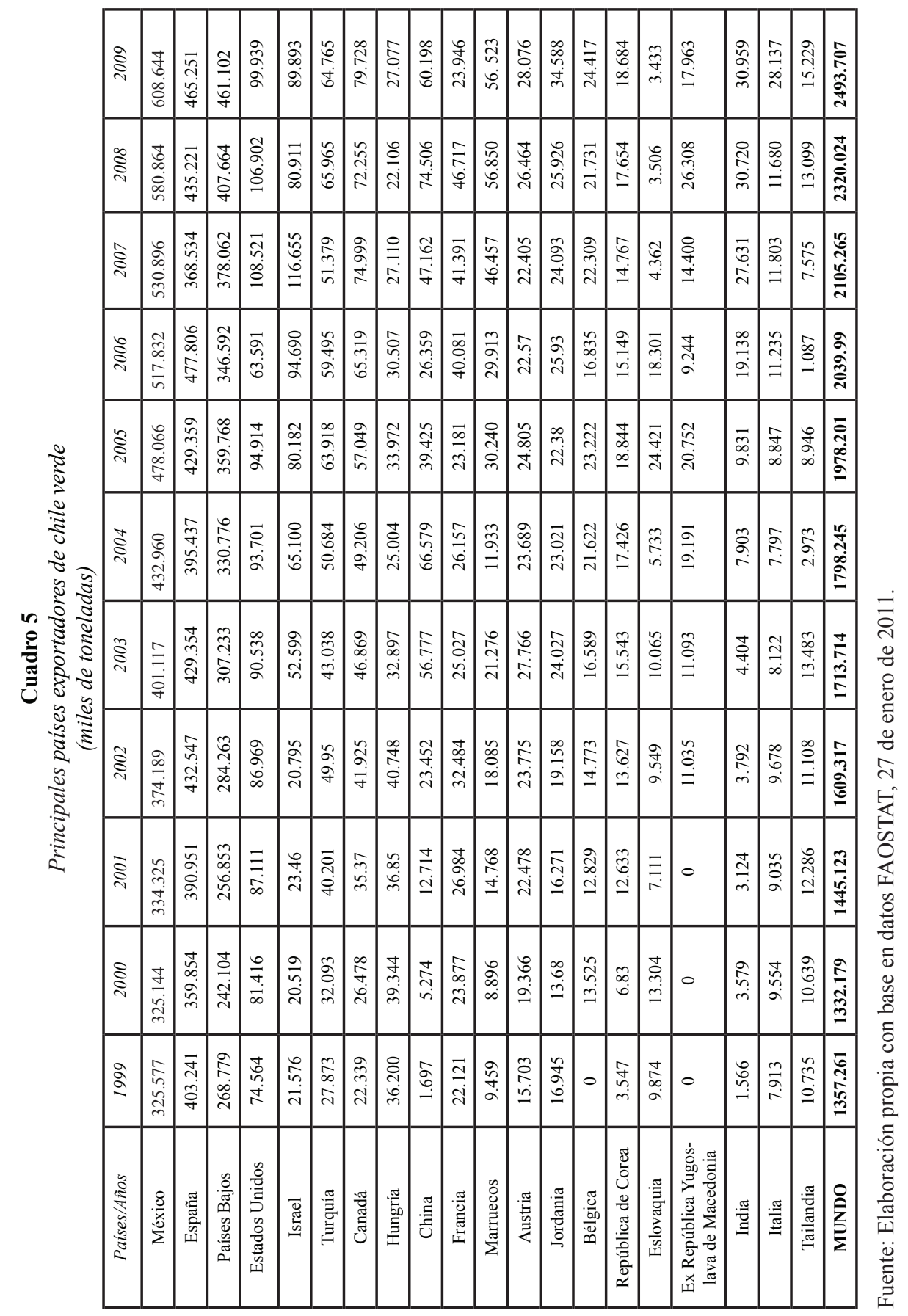

Julio - diciembre de 2014 - Págs. 95-128 
que fue de $24.41 \%$ en 2009 y en 1999 representó sólo $23.99 \%$ de este total (su mayor contribución fue de $25.38 \%$ en 2006 y la menor de $23.13 \%$ en el año 2001).

A México le sigue en importancia España con un volumen de exportación que se incrementó de 403.24 a 465.25 miles de toneladas en el periodo, lo que representa una participación promedio en el total mundial de $23.43 \%$. Cabe destacar que este país ocupa el segundo lugar en las exportaciones porque su tasa de crecimiento promedio en el periodo fue baja, ( $2 \%$ ), en comparación con la de México que fue de $6.70 \%$. Por su parte, Países Bajos que ocupaba el doceavo lugar en la producción mundial de chiles verdes, tiene el tercer lugar de las exportaciones mundiales con una contribución promedio de $18.08 \%$. Después de este país, los porcentajes de participación en las exportaciones descienden notablemente, por ejemplo, Estados Unidos ( $4^{\circ}$ lugar), Israel ( $5^{\circ}$ lugar) y Turquía $\left(6^{\circ}\right)$ registraron valores de $5.35 \%, 3.29 \%$ y $2.88 \%$, respectivamente.

En general la oferta de exportación del chile verde en el mercado mundial siguió un comportamiento ascendente casi en forma lineal durante el periodo 1999-2009 al registrar una tasa de crecimiento media anual de $6.6 \%$, la cual resultó mayor en 2.67 puntos porcentuales en comparación con la tasa registrada por la producción mundial de este cultivo. En términos absolutos, la oferta pasó de 1,357.26 miles de toneladas en 1999 a 2,493.71 miles toneladas en 2009, incremento aproximado de 1.9 veces, que representa, en general, el ritmo de crecimiento de las necesidades de su demanda para consumo en fresco, procesado o para uso industrial.

Es importante señalar que los tres principales países exportadores de chiles verdes en el periodo 1999-2009, México, España y Países Bajos, concentraron en promedio $65.73 \%$ del total de la oferta externa mundial. Las cifras ofrecen una idea de la estructura y concentración del comercio 
internacional del chile verde, ya que la diferencia de estos tres países con Estados Unidos, que se ubica como el cuarto exportador mundial, es significativa; éste último aporta en promedio 5.35\% del mercado externo. En particular, de los tres países principales que conforman el volumen de la oferta externa de pimientos verdes, destaca el comportamiento del volumen de exportación de México, que resultó el más dinámico entre 1999 y 2009 al crecer 86.94 puntos porcentuales; le siguieron en importancia Países Bajos (71.55\%) y España (15.38\%). De este grupo exportador es importante señalar que la India, como en el caso de China $(3,447.44 \%)$, incrementó su participación en el mercado mundial en forma muy significativa (1,884.61\%), al pasar de 1.56 a 30.96 miles de toneladas en el periodo. Así, estos dos últimos países con creciente participación en el mercado mundial, que poseen diferentes ventajas competitivas (Porter, 2008), son los que en los próximos años influirán en la nueva redistribución del comercio mundial del chile verde.

\section{INDICADORES DE COMPETITIVIDAD DE LOS PRINCIPALES PAÍSES PRODUCTORES}

\subsection{Indicador de transabilidad}

Como se puede observar en el cuadro 6, de acuerdo con este indicador de los 15 principales países productores de chile verde en el mundo, Países Bajos ocupa el primer lugar en competitividad, ya que tiene la capacidad de enviar al mercado internacional (apertura exportadora) una cantidad de chile verde equivalente a 6.87 veces su consumo interno y de necesitar del exterior (penetración de importaciones) una proporción de sólo 1.54; la diferencia entre ambos, expresado en porcentaje, es de 533.36\% y representa el exceso de oferta en su mercado interno. 


\section{CUADRO 6}

Indicador de transabilidad de los principales países productores de chile verde

\begin{tabular}{|c|c|c|c|c|c|}
\hline $\begin{array}{c}\text { Posición } \\
\text { competi- } \\
\text { tiva }\end{array}$ & Países & Característica & $\begin{array}{c}\text { Grado de } \\
\text { apertura } \\
\text { exporta- } \\
\text { dora } \\
(\%)\end{array}$ & $\begin{array}{c}\text { Grado de } \\
\text { penetración } \\
\text { de importa- } \\
\text { ciones } \\
(\%)\end{array}$ & $\begin{array}{c}\text { Indicador } \\
\text { de tran- } \\
\text { sabilidad } \\
\quad \% \text { ) }\end{array}$ \\
\hline 23 & China & Exceso de oferta & 0.31 & 0.03 & 0.28 \\
\hline 6 & México & Exceso de oferta & 34.94 & 0.40 & 34.54 \\
\hline 17 & Turquía & Exceso de oferta & 3.11 & 0.01 & 3.10 \\
\hline 4 & España & Exceso de oferta & 76.56 & 2.34 & 74.21 \\
\hline 48 & $\begin{array}{l}\text { Estados } \\
\text { Unidos }\end{array}$ & Exceso de demanda & 7.38 & 37.77 & -30.39 \\
\hline 29 & Indonesia & Exceso de oferta & 0.09 & 0.02 & 0.07 \\
\hline 34 & Nigeria & Exceso de demanda & 0 & 0.01 & -0.002 \\
\hline 21 & Egipto & Exceso de oferta & 0.55 & 0 & 0.55 \\
\hline 16 & $\begin{array}{l}\text { República } \\
\text { de Corea }\end{array}$ & Exceso de oferta & 3.62 & 0.01 & 3.61 \\
\hline 47 & Italia & Exceso de demanda & 2.67 & 15.28 & -12.61 \\
\hline 1 & $\begin{array}{l}\text { Países } \\
\text { Bajos }\end{array}$ & Exceso de oferta & 686.93 & 153.57 & 533.36 \\
\hline 27 & Ghana & Exceso de oferta & 0.07 & 0.01 & 0.07 \\
\hline 28 & Túnez & Exceso de oferta & 0.07 & 0.003 & 0.07 \\
\hline 31 & Argelia & Exceso de oferta & 0.01 & 0 & 0.01 \\
\hline 41 & Rumania & Exceso de demanda & 0.05 & 2.83 & -2.77 \\
\hline
\end{tabular}

Fuente: Estimación propia con datos de 1998 a 2009, FAOSTAT, 2011.

El segundo lugar del grupo lo ocupa Jordania con un índice de transabilidad de $157.74 \%$, el tercero le corresponde a Israel $(81.82 \%)$, en tanto que el cuarto y quinto lo tienen España y Guatemala, con indicadores de $65.34 \%$ y $44.53 \%$, respectivamente.

México se encuentra en el $6^{\circ}$ lugar de competitividad en este rubro, con un indicador de transabilidad de $34.54 \%$, por lo que también presenta 
un excedente de oferta y su indicador resulta superior en relación con el de países como China (primer productor mundial), Turquía (tercer productor mundial), Egipto, República de Corea, Ghana, India, República Dominicana y Côte d'Ivoire. Por lo tanto, México tiene la capacidad de enviar al mercado internacional (apertura exportadora) una cantidad de chile verde equivalente a 0.34 veces su consumo interno y de necesitar del exterior (penetración de importaciones) una proporción de sólo 0.004 veces (Villegas y Zapata, 2007).

Asimismo, hay que destacar que el elevado signo negativo del indicador de transabilidad de Francia hace evidente que este país requiera del exterior muchísima mayor cantidad de chile verde que lo que envía a otros países. De tal manera que presenta un excedente de demanda o déficit de consumo de $80.87 \%$ en su mercado interno, el cual tiene que satisfacer con producto externo, lo que representa una alternativa de venta para los países que producen y exportan (Fouquin, 1986) dicha hortaliza hacia el citado país europeo. En esta misma situación se encuentran Estados Unidos (-30.39\%), Japón (-12.57\%), Italia (-12.61\%) y Canadá (-55\%).

Por lo antes señalado, se puede decir que México está en posición de exportar el excedente de chile verde que le queda después de satisfacer su consumo interno (Casar, 1993); lo cual representa una oportunidad viable de exportación, con un producto competitivo, hacia aquellos países con exceso de demanda (Michalet, 1981). Hay que resaltar que Estados Unidos, Japón y Canadá, que presentan también índices de transabilidad negativos, son clientes de México desde hace ya bastante tiempo en cuanto a este cultivo.

\subsection{Indicador de balanza comercial relativa (BCR)}

Con base en este indicador, en el cuadro 7 se enlistan los índices de los principales países productores de chile verde en el mundo, en el se puede 
observar que sólo hay un país con un valor de 100\% en su índice, Egipto. Sin embargo, existen otros tres países, entre los 50 más importantes, que presentan la misma condición y que, además, corresponden a países netamente exportadores; Irán, con un saldo en su balanza comercial a favor de 80,238 miles de toneladas, República Dominicana con 56,912 miles de toneladas y Uzbekistán con 43,284 miles de toneladas de chile verde.

CUADRO 7

Indicador de la balanza comercial relativa de los principales países productores de chile verde

\begin{tabular}{|c|c|c|c|c|}
\hline $\begin{array}{c}\text { Posición } \\
\text { competitiva }\end{array}$ & Países & $\begin{array}{c}\text { Indicador de ba- } \\
\text { lanza comercial } \\
\text { relativa }\end{array}$ & Característica & $\begin{array}{c}\text { *Saldo neto } \\
\text { balanza } \\
\text { comercial }\end{array}$ \\
\hline 22 & China & $82.71 \%$ & Ventaja & 320.925 \\
\hline 14 & México & $97.74 \%$ & Ventaja & $4,548.188$ \\
\hline 11 & Turquía & $99.32 \%$ & Ventaja & 510.007 \\
\hline 15 & España & $94.06 \%$ & Ventaja & $4,386.593$ \\
\hline 42 & $\begin{array}{l}\text { Estados } \\
\text { Unidos }\end{array}$ & $-67.31 \%$ & Desventaja & $-3,941.372$ \\
\hline 27 & Indonesia & $59.72 \%$ & Ventaja & 6.364 \\
\hline 50 & Nigeria & $-100 \%$ & Desventaja & -0.150 \\
\hline 1 & Egipto & $100 \%$ & Ventaja & 27.262 \\
\hline 9 & $\begin{array}{l}\text { República de } \\
\text { Corea }\end{array}$ & $99.72 \%$ & Ventaja & 137.107 \\
\hline 43 & Italia & $-70.22 \%$ & Desventaja & -493.878 \\
\hline 25 & Países Bajos & $63.46 \%$ & Ventaja & $2,628.229$ \\
\hline 13 & Ghana & $99.55 \%$ & Ventaja & 2.037 \\
\hline 17 & Túnez & $90.59 \%$ & Ventaja & 1.636 \\
\hline 20 & Argelia & $87.12 \%$ & Ventaja & 0.203 \\
\hline 47 & Rumania & $-96.19 \%$ & Desventaja & -61.730 \\
\hline
\end{tabular}

Nota: $\left(^{*}\right)$ miles de toneladas.

Fuente: Estimación propia con base en datos de 1998 a 2009, FAOSTAT, 2011. 
De acuerdo con el indicador de la balanza comercial relativa, la posición competitiva de México en el mundo es alta, ocupa el $14^{\circ}$ lugar con un índice de $97.74 \%$, lo cual indica que tiene la capacidad para sobrepasar el nivel de producción necesario para abastecer la demanda interna del país (Caño-Guiral, 1994 ). México es más competitivo en el mercado del chile verde que algunos de los principales países productores como España (94.06\%), China (82.71\%), Países Bajos (63.46\%) e Indonesia (59.72\%). Sin embargo, es sobrepasado por otros como: India, con un indicador de 99.95\%; Israel de 99.92\%, Marruecos 99.85\%, Chile 99.78\%, República de Corea $99.72 \%$, Jordania de $99.47 \%$ (el segundo lugar de los índices de transabilidad más altos) y Turquía (tercer mayor productor de chile verde mundial) con un índice de 99.32\%. Estos países, con un indicador de balanza comercial relativamente alto, representan un sector lo suficientemente competitivo como para dedicar parte de su producción nacional a la exportación (Parkin, Muñoz, y Esquivel, 2007).

Cabe mencionar que Nigeria (-100\%), Japón (-99.98\%), Italia $(-70.22 \%)$ y Estados Unidos (-67.31\%), son países cuyo saldo negativo de sus respectivas balanzas comerciales les confiere, con base en este indicador, una condición de desventaja (Ministerio de Fomento, Industria y Comercio de Nicaragua, 2009). En esta situación, influye de manera muy importante la capacidad que tiene cada país para asignar mayores recursos, como el factor tierra, para incrementar su producción y con ello reducir su déficit comercial. Pero, según la disponibilidad de dichos recursos o de la valoración de los costos de oportunidad que se haga de ellos en su uso en otras actividades (Oster, 2000), decidirán si éstos se asignan a la producción de chile verde o si continúan dependiendo del mercado internacional. 


\subsection{Indicador de especialización}

Con base en la información que se presenta en el cuadro 8 se comprueba que México es el país que posee la más alta especialización y competitividad en el mercado mundial de chile verde (24.01\%) y una alta vocación exportadora, ya que presenta el $24.29 \%$ de participación en las exportaciones mundiales. En segundo lugar se encuentra España que presenta una especialización del $23.16 \%$ e igualmente un alto grado de participación en las exportaciones $(23.89 \%)$, en tanto que el tercer país con elevado grado de especialización en este producto es Países Bajos (13.87\%). Los otros seis países que presentan un indicador de especialización por arriba de uno por ciento fueron: Israel (3.13\%), Turquía (2.69\%), China (1.69\%), Hungría (1.47\%), Marruecos (1.35\%) y Jordania (1.23\%).

\section{CUADRO 8}

Indicador de especialización de los principales paises productores de chile verde

\begin{tabular}{|c|c|c|c|c|}
\hline $\begin{array}{c}\text { Posición compe- } \\
\text { titiva }\end{array}$ & Países & $\begin{array}{c}\text { Grado de es- } \\
\text { pecialización } \\
(\%)\end{array}$ & Característica & $\begin{array}{c}\text { Participación } \\
\text { exportaciones } \\
\text { en el mundo } \\
(\%)\end{array}$ \\
\hline 6 & China & 1.69 & Bajo & 1.87 \\
\hline 1 & México & 24.01 & Alto & 24.29 \\
\hline 5 & Turquía & 2.69 & Bajo & 2.70 \\
\hline 2 & España & 23.16 & Alto & 23.89 \\
\hline 50 & Estados Unidos & -20.80 & Bajo & 5.05 \\
\hline 23 & Indonesia & 0.03 & Bajo & 0.04 \\
\hline 35 & Nigeria & -0.001 & Bajo & 0 \\
\hline 19 & Egipto & 0.14 & Bajo & 0.14 \\
\hline 10 & $\begin{array}{l}\text { República de } \\
\text { Corea }\end{array}$ & 0.72 & Bajo & 0.72 \\
\hline 47 & Italia & -2.61 & Bajo & 0.55 \\
\hline 3 & Países Bajos & 13.87 & Alto & 17.87 \\
\hline 27 & Ghana & 0.01 & Bajo & 0.01 \\
\hline 28 & Túnez & 0.01 & Bajo & 0.01 \\
\hline 31 & Argelia & 0.001 & Bajo & 0.001 \\
\hline 41 & Rumania & -0.33 & Bajo & 0.01 \\
\hline
\end{tabular}

Fuente: Estimación propia con base en datos 1998 - 2009, de FAOSTAT, 2011. 
Aunque los mayores índices de especialización a nivel mundial se encuentran en los tres primeros lugares de esta lista (México, España y Países Bajos), el hecho de que existan otros países con índices por arriba de $1.0 \%$ (menor especialización), indica que cada vez hay más países que pueden competir con cierta ventaja en el mercado del chile verde.

Los países de América que presentan algún grado de especialización son Guatemala (0.44\%), República Dominicana (0.30\%), Chile $(0.04 \%)$, Venezuela $(0.02 \%)$, y Colombia $(0.01 \%)$, mismos que resultan muy bajos. Por su parte, en el cuadro 8 se puede observar igualmente que Estados Unidos es el país con el índice más bajo de especialización, de la lista de los 50 principales países productores de chile verde en el mundo, $-20.80 \%$; a pesar de que cuenta con $5.05 \%$ de participación en las exportaciones. Por lo que no presenta algún grado de especialización en el mercado internacional de los pimientos verdes; característica que comparten otros países como Francia (-5.15\%), Italia (-2.61\%) y Japón (-1.18\%).

Finalmente, se puede inferir que México presenta una alta ventaja competitiva y marcada vocación exportadora en el mercado mundial de los pimientos frescos, pero ésta podría ser mayor todavía si se incrementa la productividad por hectárea (Endon y Morales, 2006), ya que la base real de integración y permanencia en el mercado es un costo medio relativamente menor (Chesnais, 1981). Por ejemplo, la productividad por hectárea en México creció a una tasa media anual de 4.5\% en el periodo de 1999 a 2009, lo cual es bajo si se compara con Finlandia, donde esta variable creció $15.09 \%$ (FAOSTAT, 2012). 


\section{CONCLUSIONES}

En el presente estudio se ejemplifica que una excelente herramienta estadística para medir la competitividad de un producto es el índice de ventajas comparativas reveladas. Dicho índice mide la competitividad de los productos manufacturados mediante datos de flujo comercial, y no de precios relativos. Supone que el patrón comercial de los productos refleja los costos relativos, así como las diferencias de factores en calidad y servicio.

El volumen de producción de chiles verdes en el contexto mundial ha tenido una dinámica importante al presentar una tendencia al alza, en el periodo de 1999 a 2009, con un crecimiento total de $46.69 \%$. El volumen de producción de Asia es el más importante a este nivel, destaca China como el mayor productor (en 2009 su volumen representó $51 \%$ de la producción mundial). En el caso de México, su producción se caracterizó también por un comportamiento ascendente, ocupa actualmente el segundo lugar como productor mundial; sin embargo, en términos generales durante el periodo 1999-2009 su tasa media anual de crecimiento fue de sólo $2.13 \%$, por debajo de la mundial que fue de 3.93 por ciento.

En lo que se refiere al comercio internacional de este producto, la oferta de exportación del chile verde en el mercado mundial también siguió un comportamiento ascendente, casi en forma lineal, de 1999 a 2009 (con una tasa de crecimiento media anua de 6.6\%); entre los principales países exportadores de chile verde se encuentra México en primer lugar, y le sigue en importancia España y Países Bajos. Para el caso de México, el comportamiento del volumen de exportaciones de chile verde también fue ascendente (tasa media de crecimiento de 6.7\%).

Por lo que respecta a la competitividad internacional del producto en cuestión, el indicador de transabilidad muestra a Países Bajos, Jordania 
e Israel como los principales países con vocación exportadora en el mundo. Países Bajos muestra la mayor vocación al tener la capacidad de enviar al mercado internacional una cantidad equivalente a 6.87 veces su consumo interno; México, por su parte, únicamente tiene capacidad de exportar el equivalente a tres veces su consumo interno. En cuanto al indicador de balanza comercial relativa, éste evidencia que existe un buen número de países competitivos en el mercado mundial de los chiles verdes (encabezan Irán, República Dominicana, Uzbekistán y Egipto), ya que exportan más de lo que importan de chiles verdes en el mercado mundial. Sin embargo, Países Bajos muestra un alto indicador de especialización al tener sus exportaciones una participación muy importante en el mercado mundial del producto. Por otra parte, el mismo indicador pone a México como el país que posee la más alta especialización y competitividad en el mercado internacional de chile verde, le siguen en importancia España e Israel.

Por último se concluye que se acepta la hipótesis planteada, dado que la tendencia favorable observada en la oferta y el comercio mundial del chile verde durante el lapso 1999- 2009 sí se ha visto reflejada de manera importante en México, ya que se incrementó tanto su volumen de producción como el de sus exportaciones de pimientos en el periodo, lo cual, a su vez, se evidencia en la alta competitividad de los pimientos nacionales, expresado en su índices positivos de transabilidad, de balanza comercial relativa y de especialización internacional. 


\section{REFERENCIAS}

Balassa, B. 1965. Trade Liberalization and "Revealed" Comparative Advantage, The Manchester School, 33(2): 99-123

Casar, José Y. 1993. La competitividad en la industria manufacturera mexicana. 1980-1990, El Trimestre Económico, LX (1).

Caño-Guiral, Maira. 1994. "La Estructura Industrial en el Uruguay y el Proceso de Apertura Económica". Revista de Economía. Segunda Epoca. Vol. I No.2. Banco Central del Uruguay. Disponible en:http://www.banguat.gob.gt/inveco/notas/articulos/envolver. asp? karchivo $=2801 \& \mathrm{kdisc}=\mathrm{si}$

Chesnais, F. 1981. La competitividad internacional principales cuestiones conceptuales y metodológicas. OECD, París (mimeo).

Durán Lima, J.osé Elías y M. Alvarez. 2008. Indicadores de comercio exterior y política comercial: mediciones de posición y dinamismo comercial, Documento de proyecto, CEPAL.

Endon Trejo, Araceli y A. Morales Alquicira. 2006. Flujos comerciales y competitividad en la industria del calzado, Política y Cultura, 26: 235-260, www.redalyc.org/articulo.oa?id=26702612 .

FAO. 2010. Archivo de noticias, www.fao.org/news/story/es/item/40117/ icode

FAOSTAT. 2011/2012 Modulo comercio, http://faostat3.fao.org/faostatgateway/go/to/home/E

FAOSTAT. 2011/2012. Modulo producción,http:// faostat.fao.org/site/339/ default.aspx

Fouquin M. 1986. Industrie mondiale la compétitivité ompetout Prix. Economica. París.Hernández Sampieri, R., C. Fernández Collado y P. Baptista Lucio . 2010. Metodología de la investigación, McGraw-Hill, México. 
IICA. 2005. La competitividad de las cadenas agroproductivas en Colombia, Análisis de su estructura dinámica (1991-2004), anuario 2004, Ministerio de agricultura y desarrollo rural,, Bogotá.

Inforural. 2010. México: primer lugar mundial en producción de chile verde y sexto en la de chile seco, www.inforural.com.mx/mexicoprimer-lugar-mundial-en-produccion-de-chile-verde-y-sexto-en-lade-chile-seco/

Inforural. 2012. Chile, producción nacional. Disponible en: http://www. inforural.com.mx/chile-produccion-nacional/

Kasmier, Leonard J. 2000. Estadística aplicada a la administración y a la economía, 3era. edición, Mcgraw-Hill.

Lafay, Gérard. 1979. Dynamique de la specialisation international, Economica, París.

Michalet Charles. 1981."Competitiveness and internationalization". (mimeo). OECD. Paris

Ministerio de Fomento, Industria y Comercio. 2009. Ficha producto miel de abeja, Managua, Nicaragua, www.mific.gob.ni/LinkClick. aspx?fileticket=UQb13AxmUyU\%3D \&tabid =861\&language=es-NI.

Oster, Sharon M. 2000. Análisis moderno de la competitividad, Oxford University Press, México.

Parkin, Michael, M. Muñoz y G. Esquivel. 2007. Macroeconomía; versión para Latinoamérica, $7^{\mathrm{a}}$.. edición, Pearson Education, México.

Porter, Michael. 2008. Estrategia competitiva: técnicas para el análisis de los sectores industriales y de la competencia, Grupo Editorial Patria, México.

SAGARPA. 2012. Sistema de información agroalimentaria y pesquera, www.siap.gob.mx/cierre-de-la-produccion-agricola-por-estado/.

Samuelson Paul A. y W.D. Nordhaus. 2010. Macroeconomía; con aplicaciones para Latinoamérica, McGraw-Hill, México. 
United States Departament of Agriculture. 2012. Foreing Agricultural Service. Standar query, www.fas.usda.gov/gats/ExpressQuery1.aspx.

Villegas Álvarez, Diana y H. Zapata González. 2007. Competitividad sectorial internacional. Caso: sector del cuero y del calzado, Economía, 3(1):. 24-49.

Vollrath, T. 1987. Revealed Competitive Advantage for Wheat, Economic Research Service Staff Report No. 8714. US, Department of Agriculture. 